\title{
S-Adenosylmethionine Decarboxylase Proenzyme
}

National Cancer Institute

\section{Source}

National Cancer Institute. S-Adenosylmethionine Decarboxylase Proenzyme. NCI

Thesaurus. Code C102775.

S-adenosylmethionine decarboxylase proenzyme (334 aa, $\sim 38 \mathrm{kDa}$ ) is encoded by the human AMD1 gene. This protein is involved in polyamine metabolism. 